\title{
Facilitating aging in place: A qualitative study of practical problems preventing people with dementia from living at home
}

Citation for published version (APA):

Thoma-Lurken, T., Bleijlevens, M. H. C., Lexis, M. A. S., de Witte, L. P., \& Hamers, J. P. H. (2018).

Facilitating aging in place: A qualitative study of practical problems preventing people with dementia from living at home. Geriatric Nursing, 39(1), 29-38. https://doi.org/10.1016/j.gerinurse.2017.05.003

\section{Document status and date:}

Published: 01/01/2018

DOI:

10.1016/j.gerinurse.2017.05.003

\section{Document Version:}

Publisher's PDF, also known as Version of record

\section{Document license:}

Taverne

\section{Please check the document version of this publication:}

- A submitted manuscript is the version of the article upon submission and before peer-review. There can be important differences between the submitted version and the official published version of record.

People interested in the research are advised to contact the author for the final version of the publication, or visit the DOI to the publisher's website.

- The final author version and the galley proof are versions of the publication after peer review.

- The final published version features the final layout of the paper including the volume, issue and page numbers.

Link to publication

\footnotetext{
General rights rights.

- You may freely distribute the URL identifying the publication in the public portal. please follow below link for the End User Agreement:

www.umlib.nl/taverne-license

Take down policy

If you believe that this document breaches copyright please contact us at:

repository@maastrichtuniversity.nl

providing details and we will investigate your claim.
}

Copyright and moral rights for the publications made accessible in the public portal are retained by the authors and/or other copyright owners and it is a condition of accessing publications that users recognise and abide by the legal requirements associated with these

- Users may download and print one copy of any publication from the public portal for the purpose of private study or research.

- You may not further distribute the material or use it for any profit-making activity or commercial gain

If the publication is distributed under the terms of Article $25 \mathrm{fa}$ of the Dutch Copyright Act, indicated by the "Taverne" license above, 
Feature Article

\title{
Facilitating aging in place: A qualitative study of practical problems preventing people with dementia from living at home
}

\author{
Theresa Thoma-Lürken, MSc ${ }^{\text {a,* }}$, Michel H.C. Bleijlevens, PhD ${ }^{\text {a }}$, Monique A.S. Lexis, PhD ${ }^{\text {b }}$ \\ Luc P. de Witte, PhD, MD ${ }^{c}$, Jan P.H. Hamers, PhD, RN ${ }^{\text {a }}$
}

a Maastricht University, CAPHRI Care and Public Health Research Institute, Department of Health Services Research, Living Lab on Aging and Long-Term Care, Maastricht, The Netherlands

${ }^{\mathrm{b}}$ Zuyd University of Applied Sciences, Research Centre Technology in Care, Heerlen, The Netherlands

${ }^{\mathrm{c}}$ University of Sheffield, CATCH, Centre for Assistive Technology and Connected Healthcare, Sheffield, UK

\section{A R T I C L E I N F O}

\section{Article history:}

Received 16 December 2016

Received in revised form 11 May 2017

Accepted 11 May 2017

Available online 16 June 2017

\section{Keywords:}

Aging-in-place

Community-dwelling

Dementia

Focus groups

Nurses

Practical problems

\begin{abstract}
A B S T R A C T
Although the majority of people with dementia wish to age in place, they are particularly susceptible to nursing home admission. Nurses can play an important role in detecting practical problems people with dementia and their informal caregivers are facing and in advising them on various ways to manage these problems at home. Six focus group interviews $(n=43)$ with formal and informal caregivers and experts in the field of assistive technology were conducted to gain insight into the most important practical problems preventing people with dementia from living at home. Problems within three domains were consistently described as most important: informal caregiver/social network-related problems (e.g. high load of care responsibility), safety-related problems (e.g. fall risk, wandering), and decreased selfreliance (e.g. problems regarding self-care, lack of day structure). To facilitate aging in place and/or to delay institutionalization, nurses in community-based dementia care should focus on assessing problems within those three domains and offer potential solutions.
\end{abstract}

(c) 2017 Elsevier Inc. All rights reserved.

\section{Introduction}

\section{Background}

The number of people suffering from dementia is increasing worldwide. ${ }^{1,2}$ Currently, about 260,000 people with dementia live in the Netherlands, ${ }^{3}$ and about $70 \%$ of them are living at home supported by informal and formal caregivers. ${ }^{4}$ Formal communitybased dementia care in the Netherlands basically consists of care providers such as general practitioners, home care organizations, day-care centers, and care coordinators (e.g. dementia case managers). ${ }^{5}$ Since dementia is a progressive disease characterized by cognitive and functional decline, it makes people increasingly dependent on support ${ }^{2}$ and particularly susceptible to nursing home admission. ${ }^{6}$ At the same time, the expected preference of the ma-

Funding: The study was part of a larger research project funded by the Province of Limburg, The Netherlands (grant no. 2013/15434).

Conflicts of interest: None.

* Corresponding author. Maastricht University, CAPHRI Care and Public Health Research Institute, Department of Health Services Research, P.O. Box 616, 6200 MD Maastricht, The Netherlands.

E-mail address: t.thoma@maastrichtuniversity.nl (T. Thoma-Lürken). jority of people with dementia is to live at home as long as possible, ${ }^{1,7}$ which is also a common policy aim of many Western countries. ${ }^{1,8}$

During the last years the policy concerning the eligibility for publicly funded professional long-term care in the Netherlands has changed significantly. ${ }^{9,10}$ Where in the past people were widely supported by publicly funded professional care either at home or in long-term care facilities, people now need to live as long as possible in their own home environment. Moreover, the social network of a care dependent person is expected to fulfill as much care tasks as possible before publicly funded care can be requested..$^{9,}{ }^{10}$ These changes put new responsibilities on informal caregivers and ask for new solutions to delay or even prevent nursing home admission.

To delay nursing home admission of people with dementia it is necessary to have insight into the factors which prevent people with dementia from living at home. General predictors of nursing home admission of people with dementia have already been extensively studied, and the results are, to a large extent, summarized in two systematic reviews by Gaugler et al $^{11}$ and Luppa et al. $^{12}$ According to Luppa et al $^{12}$ the predictors can be categorized into predisposing variables (socio-demographic and relationship characteristics of patients and caregivers), needs variables (primary stressors such as severity of dementia, functional impairment and caregiving hours and secondary stressors such as caregiver burden or life satisfaction) and enabling variables (personal and social resources and 
community-based care). A recent European study ${ }^{13}$ showed that caregiver burden and dependency in activities of daily life, are the most consistent factors predicting a nursing home admission for people with dementia. In order to support people with dementia and to delay or even prevent institutionalization it is necessary to focus on potentially modifiable predicators such as caregiver burden or ADL dependencies. Consequently, this theoretical knowledge needs to be operationalized into concrete solutions to delay or even prevent institutionalization of people with dementia. To tailor (innovative) solutions first deeper insight into the underlying practical problems (daily struggles) people with dementia and their caregivers are experiencing in the daily life which prevent them from living at home is needed.

Professionals can play an important role in advising people with dementia and their informal caregivers on possible solutions and care options ${ }^{14}$ as people with dementia and their informal caregivers might not be aware of available and quickly evolving (technological) solutions. ${ }^{15}$ In community-based dementia care nurses in the function of district nurse or and case manager often fulfill this advisory role. Hence, nurses need to have insight into most important the practical problems people with dementia and their informal caregivers are experiencing, that prevent them from living at home. Those problems should be addressed first in an attempt to delay or prevent nursing home admission.

\section{Aim}

Therefore, the aim of this study was to gain deeper insight into the most important practical problems preventing people with dementia from living at home. These insights may inform nurses in community-based dementia care how to target their assessments as well as their advice on possible solutions to delay or prevent institutionalization.

\section{Material and methods}

\section{Design}

A qualitative study using six focus group interviews was conducted to gain insight into the most important practical problems in daily life preventing people with dementia from living at home.

\section{Sample/participants}

A purposive sampling method was applied so that participants were selected who are regarded as particularly knowledgeable about the topic under consideration and can provide relevant information. ${ }^{16}$ Therefore, we chose important stakeholders involved in different phases of community-based dementia care. Those stakeholders were divided into three types of focus groups (A, B and C). A total of six focus group interviews were conducted. The size of the individual groups was planned to be between 6 and 11 participants. The first three focus group interviews (type A) consisted of professionals who had a direct role in care coordination for community-dwelling people with dementia (case managers, home care nurses, general practitioners, client advisors of long-term care organizations) $(n=23)$. Those professionals work with community-dwelling people with dementia on a daily basis and have experienced numerous transitions from home to a nursing home. Two focus group interviews (type B) were planned with occupational therapists, experts in the field of assistive technology, suppliers of assistive technology, and a consultant working for a non-profit organization that advises informal caregivers about their caregiving tasks $(n=14)$. The participants in this group were included because they were expected to have insight into specific practical problems in the daily life of community-dwelling people with dementia, as they are often involved in the process of solving such problems. Finally, one focus group (type C) was composed of informal caregivers of people with dementia and representatives from dementia support groups (who were also informal caregivers) $(n=6)$, as they are the ones actually "co-experiencing" the practical problems in daily life. Informal caregivers were included because they provide, to a large extent, the care for community-dwelling people with dementia. Moreover, evidence shows that they can be considered a reliable source of information on reasons for nursing home admission of people with dementia. ${ }^{17}$ All participants were recruited via the Living Lab in Aging and Long-Term Care South Limburg and via a network organization for innovative care and technology located in the south of the Netherlands.

\section{Data collection}

The six focus group interviews were held in September and October 2014. The interviews took place in a meeting room at the university and were planned to last for about $2 \mathrm{~h}$. All interviews were audio recorded with verbal consent of all participants. The interviews were led by experienced moderators (two authors [M.B., M.L.] and one other researcher) who are doctorally-prepared researchers in gerontology, assisted by one or two observers (one author [T.T.L.] and one other researcher). A topic list with two main open-ended questions (1. "What are the most important problems preventing community-dwelling patients with dementia from living at home?" If no informal caregiver-related problems were described initially, the moderator asked the following question: 2 . "What are problems informal caregivers experience that threaten the ability of people with dementia to live at home?") was used to structure the interviews. Prior to the interviews, the participants received information about the aim of the interview as well as the first main question of the topic list via email or mail. To ensure that all participants had an equal chance of expressing their opinion, the focus groups were conducted based on elements of the Metaplan method. ${ }^{18}$ According to this method, to visualize and lead group discussions, participants are asked to write down their arguments on cards, which are subsequently jointly clustered. At the start of each focus group interview, all participants were asked to write down on sticky notes what, according to them, were the three most important problems preventing people with dementia from living independently at home. To start the discussion, each member was asked to name the three most important problems. All notes were collected and jointly clustered into categories to get an overview of the problems mentioned and to verify whether important problems were missing. When no new categories emerged, it was assumed that saturation was reached. During the interviews, the observers took field notes. At the end of each interview, the participants were asked to voluntarily complete a socio-demographic questionnaire containing questions about age, gender, and their role in caring for community-dwelling people with dementia.

\section{Data analysis}

The data analysis started with collecting the sticky notes containing the most important problems according to the respondents after each focus group interview. After all interviews were conducted, the sticky notes from all six focus groups were clustered by two pairs of project team members (three authors [T.T.L., M.B., M.L.] and one other researcher) into themes indicating the problem domains, keeping in mind the clusters made during the focus group interviews. They discussed the clusters to reach consensus about the themes (subsequently described as problem domains). Based on the audio files, literal transcripts were made for each focus group 
session. The interview texts were analyzed according to the principles of qualitative content analysis. ${ }^{19}$ The first author [T.T.L.] read the entire interview text several times and highlighted passages where the interviewees expressed their opinion about the problem domains, as previously defined. All information provided about one problem domain was first summarized using condensation, which means shortening the text but preserving the essence ${ }^{19}$ for each individual interview. Subsequently, the condensed descriptions of the problem domains of all interviews were combined into one overall MS Word document. The information about the problem domains was reviewed, and content-related categories were formulated by the first author and discussed amongst the co-authors to reach consensus.

To strengthen the trustworthiness of the study, different measures were taken to meet the criteria of credibility, dependability, confirmability, and transferability, based on the framework of Lincoln and Lubba. ${ }^{20}$ Since choosing participants with various experiences can lead to a richer description of the topic under consideration and therefore increase the credibility of the results, ${ }^{19}$ a purposive sampling method was used to include various perspectives of stakeholders playing a central role in community-based dementia care. Moreover, the main problem domains were derived from the sticky notes and clustered by two pairs of researchers, who subsequently reached consensus about the problem domains. This procedure was followed by a member check where the main results were presented and discussed with a sample of former participants of focus group type $\mathrm{A}(\mathrm{N}=5)$ to further improve the credibility and dependability of the results. ${ }^{20}$ To enhance dependability, the procedures followed in this study were meticulously described, and the same topic list was used for all focus group interviews. To increase the confirmability, which means ensuring the objectivity of the data, ${ }^{21}$ the moderator summarized the main results at the end of each focus group interview and encouraged the participants to critically reflect on the results and correct or add information where necessary. Detailed descriptions of the findings backed with literal quotes from all six focus groups are provided in order to increase the transferability ${ }^{19}$ all results presented in this article were substantiated with literal quotes from all six focus groups in this article.

\section{Ethical considerations}

The study protocol was approved by the medical ethics committee of Atrium-Orbis-Zuyd (14-N-95). Information about the aim of the study and the expected burden of the focus group session was provided to all participants in advance, either by email or post. Participation in the interviews was strictly voluntary for all participants. Before the start of each interview, oral consent to contribute to the study was given by all participants. Additional written informed consent was obtained from representatives from interest groups and informal caregivers.

\section{Results}

A total of 43 participants took part in the six focus group interviews. Table 1 provides information about the composition of the focus groups and socio-demographic characteristics of the participants.

\section{Practical problems in daily life preventing people with dementia from living at home}

The participants came up with a variety of practical problems in daily life, such as problems due to insufficient food and fluid intake, wandering, or absence of a person who can detect risks and intervene in case of emergency. The participants initially reported
Table 1

Participant characteristics $(n=43)$.

\begin{tabular}{|c|c|c|}
\hline & & $N(\%)$ \\
\hline \multicolumn{3}{|c|}{ Type $\mathrm{A}(N=23)-3$ groups } \\
\hline \multirow[t]{4}{*}{ Role } & Dementia case manager & $11(48)$ \\
\hline & Home care nurse & $5(22)$ \\
\hline & Client advisor of long-term care organizations & $5(22)$ \\
\hline & General practitioner (physician) & $2(9)$ \\
\hline \multirow[t]{2}{*}{ Sex } & Male & $4(17)$ \\
\hline & Female & $19(83)$ \\
\hline \multicolumn{2}{|c|}{ Mean age } & 43,7 years (SD 11.7) \\
\hline \multicolumn{3}{|c|}{ Type B $(N=14)-2$ groups } \\
\hline \multirow[t]{4}{*}{ Role } & Occupational therapist & $4(29)$ \\
\hline & Assistive technology expert & $4(29)$ \\
\hline & Assistive technology provider & $5(36)$ \\
\hline & Informal care consultant & $1(7)$ \\
\hline \multirow[t]{2}{*}{ Sex } & Male & $3(21)$ \\
\hline & Female & $11(78)$ \\
\hline \multicolumn{2}{|c|}{ Mean age } & 41,0 years (SD 9.9) \\
\hline \multicolumn{3}{|c|}{ Type $C(N=6)-1$ group } \\
\hline \multirow[t]{2}{*}{ Role } & Informal caregiver & $4(67)$ \\
\hline & Patient representative & $2(33)$ \\
\hline \multirow[t]{2}{*}{ Sex } & Male & $2(33)$ \\
\hline & Female & $4(67)$ \\
\hline \multicolumn{2}{|c|}{ Mean age } & 68,0 years (SD 4.3 ) \\
\hline
\end{tabular}

that defining the three most important problems was challenging. In their opinion, the problems in daily life are highly determined by the individual situation, and a combination of problems may lead to a situation in which living at home may become impossible. However, when asking them to write down what first came to their minds, comparable problems within all groups were described, which could be categorized into common "problem domains": problems due to decreased self-reliance, safety-related problems, informal care/social network-related problems, behavioral problems, formal care-related problems, and cognitive decline. Those problem domains were also confirmed during the member check.

In the following paragraphs, the practical problems mentioned by the participants are described for each problem domain, starting with the most often described problem domains, followed by the less frequently mentioned problems. Table 2 provides an overview of the practical problems described within the problem domains, supported by quotations from the participants. The codes assigned to the quotes stand for FG (focus group), followed by two numbers, with the first indicating the number of the focus group (1-6) and the second indicating the number assigned to the individual participant.

\section{Decreased self-reliance of the person with dementia}

The first problem domain consistently described during all six focus group interviews was problems regarding decreased selfreliance of the person with dementia, meaning that people with dementia lost their ability to conduct, plan, and decide about normal activities of daily living (ADL) during the course of a day. A frequently described problem preventing people with dementia from living at home was decreased ability to conduct basic ADL (especially eating, drinking, washing, mobility and transfers).

Respondents frequently stressed that a lack of ability to conduct the most basic activities, such as eating and drinking, can lead to serious consequences as the following quote shows:

"What we see a lot in daily care is that people often forget to eat and forget to drink. Consequently, they become malnourished and dehydrated (...)." (FG12) 
Table 2

Overview of problem domains preventing people with dementia from living at home.

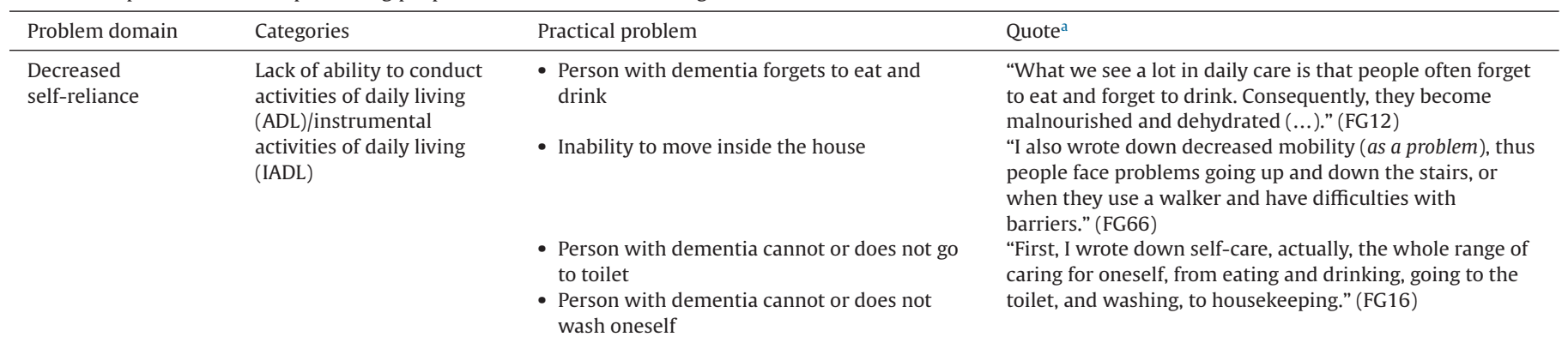

- Person with dementia cannot or does not keep their house

- Person with dementia cannot judge whether food is still edible

- Person with dementia does not know when he or she needs to clean up the house

- Person with dementia cannot use Meals on Wheels because he or she is not able to use a microwave to prepare the meal or person with dementia cannot open the door to receive 'meals on wheels'

- Person with dementia does not do grocery shopping

- Person with dementia cannot manage his or her own medication

"Not being able to take responsibility, not knowing that things (food) are moldy or at the expiration date. Not knowing when you need to clean up (the house) and also not knowing how to perform certain actions." (FG35) "This (the inability to do grocery shopping) is compensated for by Meals on Wheels, or something comparable, but the fact that people cannot open the door to receive these meals and cannot warm up the meal because of having to use a microwave becomes more and more challenging, (makes this solution insufficient)." (FG13)

"And often, there is nothing to eat and drink at home because people don't go grocery shopping." (FG11) "Medication use is also a huge problem related to selfmanagement (...)." (FG31)

"To take them at the right time?" (Moderator) "Yes, to swallow it. Besides, everything is mixed up and medication packages are scattered everywhere. To give up this self-management is very difficult for people." (FG31)

- Person with dementia cannot find things at home

- Person with dementia stores things in unusual places at home

- Person with dementia cannot handle financial administration

Lack of structure

Lack of meaningful activities

Disrupted day/night rhythm

Inability to make own decision and to judge risks

problems
- Person with dementia lacks the ability to make own decisions and to judge risks

- Person with dementia has no daily structure and does not know what to do at a particular moment during the day

- Person with dementia has no meaningful content during the day

- Person with dementia loses a normal day/ night rhythm

- Person with dementia forgets to switch off the gas, which leads to fire hazard

- Person with dementia cannot safely use electronic devices
"She got more and more chaotic in her head and in daily

life; she continued to wash (clothes) and to iron, but storing things went wrong. You would find different things in the wrong places, for example, she stored the cutlery in the wrong place after washing, or she lost the keys, those kinds of things." (FG46)

"The IBAN number, which you need to use for bank transfers, leads to huge problems. In the past, one could go to the bank counter, but nowadays you need to be happy with one ATM in the village." (FG33)

"In the first instance, I wrote down scheduling and daily structure. That is very difficult when people don't know what time it is and what it is that they need to do at a particular moment in time. That is very uncomfortable for them, but may be also for the family. Family is frequently called, or people need a lot of attention. This leads to a lot of insecurity and agitation." (FG51)

“(...) In addition to what he (another participant) said regarding a lack of structure, they (people with dementia) don't spend their day in a meaningful way. (One example is) a person who sits apathically in a chair the whole day long and who doesn't know what to do." (FG27)

"The third (problem), and for me the most important one, is that people lose their day and night rhythm. They lose their feeling for time; consequently, they don't know when they need to eat and their normal feeling of being hungry is also gone. They don't drink enough, causing dehydration and-related problems." (FG210)

“(...) The loss of self-reliance and independence, (...), the ability to make your own decisions when it is necessary. Additionally, the ability to identify risks. That is gone. When a person has partially or completely lost this ability, another person needs to detect the risk." (FG57) "Once, I (an informal caregiver) noticed fire inside my house because the gas was not switched off." (FG42) "In addition (to other problems), I have dangerous behavior; for example when a person uses scissors to cut the wire of a lamp because he/she doesn't know how to switch off the light anymore." (FG12) 
Table 2 (continued)

\begin{tabular}{|c|c|c|c|}
\hline Problem domain & Categories & Practical problem & Quote $^{\mathrm{a}}$ \\
\hline & & $\begin{array}{l}\text { - Person with dementia has a high risk of fall } \\
\text { incidents }\end{array}$ & $\begin{array}{l}\text { "(...) Fall incidents or the risk of fall incidents. Often } \\
\text { people have an unstable balance, but when the person falls } \\
\text { and breaks his/her hip, then this is finally the decisive } \\
\text { reason for (nursing home) admission." (FG12) }\end{array}$ \\
\hline & & $\begin{array}{l}\text { - Strangers entering the house of the person } \\
\text { with dementia }\end{array}$ & $\begin{array}{l}\text { "As the third one (problem), I have dangerous situations - } \\
\text { fall risk, fire hazard - but also clients (People with } \\
\text { dementia) who live alone in rural areas where strangers } \\
\text { try to enter; we had that several times. We wanted to } \\
\text { admit the person (to a nursing home), because it became } \\
\text { too risky, especially in the winter time." (FG28) }\end{array}$ \\
\hline & & $\begin{array}{l}\text { Person with dementia takes too much or too } \\
\text { little medication }\end{array}$ & $\begin{array}{l}\text { "Medication, and particularly the medication errors that } \\
\text { can occur when the medication is managed by the } \\
\text { person (with dementia) themselves or when the } \\
\text { medication is stored in a place where the person has } \\
\text { access to it. What you see is that people forget that they } \\
\text { have already taken their medication. They take the } \\
\text { medication several times, or they forgot to take it, which } \\
\text { also leads to serious health risks." (FG12) }\end{array}$ \\
\hline & & $\begin{array}{l}\text { - Person with dementia who wanders on the } \\
\text { motorway during the night, leading to } \\
\text { unsafe situations in traffic } \\
\text { - Person with dementia who wanders and } \\
\text { gets lost } \\
\text { - Person with dementia wears clothes that are }\end{array}$ & $\begin{array}{l}\text { "Hazard for the person him/herself or for the environment. } \\
\text { If a person searches for ice cream on the motorway during } \\
\text { the night, I think we (as professionals) are too late." (FG33) } \\
\text { "I wrote down (the following problems) wandering and } \\
\text { getting lost. Thus, people go outside, wearing too little } \\
\text { clothing and can't find their way back." (FG61) }\end{array}$ \\
\hline
\end{tabular}

not appropriate for the temperature

- Unsafe handling of finances

Lack of supervision

Informal care/social network-related problems
High load of care responsibilities for informal caregivers
- Lack of a person who identifies risks and undertakes actions to compensate for the deficiency of the person with dementia to judge risks

- Load of the care responsibilities placed up on the informal caregiver exceeds the capabilities of the caregiver
- Insufficient recovery time of the informal caregiver leads to higher burden

Inability to handle the person

Lack of availability of informal caregivers
- Informal caregiver does not know how to deal with the person with dementia

- No or too little availability of informal caregivers to compensate for deficiencies of the person with dementia and to provide social and emotional support

- No or few informal caregivers are available

- Informal caregiver is no longer able to care
"Safety also includes (the following situation) a person with dementia going to the bakery to buy bread for 50 euros and does this 60 times a day. (...) We have had this situation once where a person went to the florist 10 times a day to buy flowers for 20 euro. (...) This is not a risk in itself, because he knows his way back, but it costs a lot of money and the person doesn't know it." (FG35)

"Lack of a signaling function at home, thus there is nobody who intervenes when a situations is about to go wrong. (...) To identify risks on time, for example when the gas is switched on." (FG13)

"For me, the primary problem was the burden for the informal caregiver. As long as the informal caregiver can manage it well, then it usually still works. (...) The informal caregiver doesn't only get the tasks he/she already had to do, but he/she also gets additional tasks that the person with dementia can no longer conduct by himself or herself. But also because the person with dementia requires a lot of attention, which causes less available time for the caregiver to complete all of the tasks. This leads to overburdening the informal carer." (FG67) "If you have time to sleep at night then you (the informal caregivers) are able to handle it, but when it becomes $24 \mathrm{~h}$ care, when you need to be alert continuously during the night and you wake up all the time because your partner who is lying next to you starts wandering and wants to leave the house, (...) that is when things get out of hand (...)." (FG46)

"And also (in addition to other problems mentioned earlier) the high burden to informal caregivers, which is sometimes combined with an inability to deal with dementia and everything related to dementia (...)." (FG13) "As the third (problem), I wrote down none or too little informal care. Because you see that people, who have several informal caregivers around them, get by (living at home) for a longer period of time, because they get more practical things done and also get more social and emotional support, on all domains actually. And thus they run a smaller risk, for example, with regard to too little eating and drinking." (FG14)

"The first (problem) concerns little or no informal care. Sometimes there is no informal caregiver and sometimes the informal caregiver is no longer able to care and these are often points in time when the situation escalates. Then you see, especially when the person is in a more advance stage of the dementia process and when there is only (professional) home care to support the person, that it gets out of hand." (FG34) 
Table 2 (continued)

\begin{tabular}{|c|c|c|c|}
\hline Problem domain & Categories & Practical problem & Quote $^{\mathrm{a}}$ \\
\hline & & $\begin{array}{l}\text { - Sudden loss of an informal caregiver for } \\
\text { example due to illness of the informal } \\
\text { caregiver }\end{array}$ & $\begin{array}{l}\text { "Lack of a safety net regarding informal care. Children are, } \\
\text { due to their responsibilities at work, often unable to keep } \\
\text { an eye on mom and dad } 24 \text { h a day (...) or married couples } \\
\text { from which the healthy partner suddenly becomes ill or } \\
\text { unable to perform the same tasks as before, then literally } \\
\text { the whole world collapses, and we have a huge problem." } \\
\text { (FG35) } \\
\text { Another participant said: } \\
\text { "I (an informal caregiver) need to undergo two knee joint } \\
\text { replacements, but that is impossible (due to informal care } \\
\text { responsibilities)." (FG42) }\end{array}$ \\
\hline & Loss of social contacts & - Loss of social contacts & $\begin{array}{l}\text { "Aggressive behavior against other people, which causes } \\
\text { those people to visit them less frequently and for that } \\
\text { reason, probably are also unable to provide support (for } \\
\text { the person with dementia)." (FG62) } \\
\text { Additional statement by another participant: } \\
\text { "Loss of social contacts, this is very important. I think that } \\
\text { it is not necessarily caused by behavioral problems. If, } \\
\text { during a birthday party, a person asks "when are we going } \\
\text { home" } 20 \text { times, this is not aggressive behavior, but } \\
\text { perhaps this is a reason for the informal caregiver to } \\
\text { decide to no longer go there (to visit friends or attend a } \\
\text { party)." (FG67) }\end{array}$ \\
\hline \multirow[t]{2}{*}{ Behavioral problems } & Refusal of care & $\begin{array}{l}\text { - Person with dementia neglects that he/she } \\
\text { needs help/support, which can lead to } \\
\text { hazardous situations }\end{array}$ & $\begin{array}{l}\text { "Lack of insight in the disease, which causes resistance and } \\
\text { unwillingness to accept care. Those people don't want the } \\
\text { involvement of others; this quickly leads to hazardous } \\
\text { situations and risks for the persons themselves and for } \\
\text { others." (FG14) } \\
\text { Another participant said: } \\
\text { "What I also want to indicate is acceptance of help and } \\
\text { resistance against care. (...) Often this goes hand in hand } \\
\text { with dementia; that one doesn't want to accept and } \\
\text { doesn't want to see what is going on." (FG24) }\end{array}$ \\
\hline & Behavioral problems & $\begin{array}{l}\text { - Specific behavior (e.g. aggression, anxiety) is } \\
\text { difficult to handle for the informal caregiver }\end{array}$ & $\begin{array}{l}\text { "I think that when a person with dementia exhibits certain } \\
\text { behavior, especially when there is a partner, and the } \\
\text { person with dementia is difficult to handle, difficult to } \\
\text { manage, querulant, maybe aggressive, verbally or } \\
\text { physically, that this can lead to a situation in which the } \\
\text { partner is not able to deal with the situation any } \\
\text { longer." (FG34) } \\
\text { "Anxiety and suspiciousness of the person with dementia. } \\
\text { In the beginning it is a problem because the } \\
\text { suspiciousness is caused by memory problems, } \\
\text { forgetfulness; this means that people ask the same } \\
\text { question five, six, seven times within } 2 \text { min. That drives } \\
\text { you crazy." (FG45) }\end{array}$ \\
\hline \multirow[t]{3}{*}{$\begin{array}{l}\text { Formal care-related } \\
\text { problems }\end{array}$} & $\begin{array}{l}\text { Lack of suitable care } \\
\text { services }\end{array}$ & - Lack of suitable day care facilities & $\begin{array}{l}\text { "And suitable day care is not available. (...) There is day } \\
\text { care but it is not suitable in the sense that it doesn't fit to } \\
\text { the specific phases of dementia; there are not enough } \\
\text { skilled professionals, there is not enough staff, and the } \\
\text { activities are not suitable for a variety of different people } \\
\text { with dementia. Therefore, I think, or we think, that it is not } \\
\text { suitable enough." (FG25) }\end{array}$ \\
\hline & & - Lack of availability of respite care facilities & $\begin{array}{l}\text { "What I (an informal caregiver) really miss are easily } \\
\text { accessible places for people with dementia to stay } \\
\text { overnight (...) to give me (the informal caregiver) the } \\
\text { possibility to recover, to catch my breath, which would } \\
\text { enable me to continue (the informal care) for a while." } \\
\text { (FG44) }\end{array}$ \\
\hline & $\begin{array}{l}\text { Bad coordination of care } \\
\text { services }\end{array}$ & $\begin{array}{l}\text { Formal care for a person with dementia at } \\
\text { home is not well coordinated, leading to } \\
\text { agitation and stress for informal caregivers }\end{array}$ & $\begin{array}{l}\text { "Often we (professional care givers) don't know from each } \\
\text { other whether we are involved with a client." (FG16) } \\
\text { Reaction of another participant: } \\
\text { "And this is very bad; it causes a lot of agitation and often } \\
\text { also causes extra burden (stress overload) for informal } \\
\text { caregivers." (FG11) }\end{array}$ \\
\hline Cognitive decline & Cognition & $\begin{array}{l}\text { - Person with dementia's loss of ability to } \\
\text { recognize things }\end{array}$ & $\begin{array}{l}\text { "The ability to recognize certain things, loss of } \\
\text { recognition." (FG55) }\end{array}$ \\
\hline
\end{tabular}

\footnotetext{
a The words written in italics have been added by the author to make the quotation more easily understandable.
} 
Moreover, an inability to conduct higher-order activities/ instrumental activities of daily living (IADL), such as housekeeping and medication management, and difficulties regarding financial administration are also considered problems preventing people with dementia from continuing to live at home. Additionally, the participants emphasized that a lack of ability to structure the sequence of daily activities, a lack of meaningful activities, and a disrupted day/night rhythm also threaten the ability of people with dementia to live at home as the following quote indicates:

"The third (problem), and for me the most important one, is that people lose their day and night rhythm. They lose their feeling for time; consequently, they don't know when they need to eat and their normal feeling of being hungry is also gone. They don't drink enough, causing dehydration and-related problems." (FG210)

\section{Safety-related problems}

The second major problem domain consistently described during all focus group interviews was safety-related problems. These problems include an inability to judge risk and make independent decisions, dangerous situations for people with dementia or their environment, and a lack of safety measures to prevent dangerous situations. One participant (an informal caregiver of a person with dementia) described a dangerous situation as follows:

"Once, I noticed fire inside my house because the gas was not switched off." (FG42)

The participants described additionally various other safety hazards such as improper use of electronic devices, the risk of being mistreated or robbed by strangers entering the house, the risk of falling incidents, unsafe behaviors in traffic, unsafe handling of finances, and the risk of getting lost outside the house and not being able to find the way back home. Moreover, the risks of healthrelated problems due to improper medication use, insufficient intake of food and liquids, or wearing clothes that are not appropriate for the temperature were discussed. Another frequently reported problem was the absence of a "supervision function" to detect possible risks for the person with dementia as the following quote shows:

"Lack of a signaling function at home, thus there is nobody who intervenes when a situations is about to go wrong. (...) To identify risks on time, for example when the gas is switched on." (FG13)

As described earlier, people with dementia can lose their ability to judge risks and to act in a reasonable way to prevent safety hazards. Therefore, they need to be supported in the judgment of risks and regarding interventions in case of emergency. If this "supervisor" is lacking, this might hinder the ability to live at home.

\section{Informal care/social network-related problems}

The third problem domain described during all six focus group interviews are informal care/network-related problems. This domain includes problems concerning excessive informal caregiver's responsibility, the inability of the informal caregiver to properly handle the person with dementia, a lack of availability of informal caregivers, and the loss of social contacts of the person with dementia. Informal caregivers can compensate, to a certain extent, for their deficits in functional abilities and safety judgment. This can be very burdensome for the informal caregivers, especially when the person with dementia requires attention and support $24 \mathrm{~h}$ a day as illustrated by the following quote:

"If you have time to sleep at night then you (the informal caregivers) are able to handle it, but when it becomes $24 \mathrm{~h}$ care, when you need to be alert continuously during the night and you wake up all the time because your partner who is lying next to you starts wandering and wants to leave the house, (...) that is when things get out of hand (...)." (FG46).

In cases in which the burden exceeds the personal limit of the informal caregiver, the ability of the person with dementia to stay at home can be threatened. Another problem mentioned was that informal caregivers misinterpret the behaviors of the person with dementia. Problems with dealing with difficult behavior may occur when a caregiver lacks the ability to empathize with the perceptions of the person with dementia. When people know that certain behaviors are a consequence of the disease, it might be easier for them to accept those behaviors. Another frequently described problem is the lack of available informal caregivers as the following quote illustrates:

"Lack of a safety net regarding informal care. Children are, due to their responsibilities at work, often unable to keep an eye on mom and dad 24 h a day (...) or married couples from which the healthy partner suddenly becomes ill or unable to perform the same tasks as before, then literally the whole world collapses, and we have a huge problem." (FG35)

It seems that people who have no informal caregivers at all or who have a small social network, such as when they have no children or the family members live too far away, are less likely to remain living at home. A situation in which an informal caregiver is suddenly unable to provide care due to various reasons (e.g. hospital stay) can also seriously threaten the ability of people with dementia to live at home. Finally, the loss of social contacts was described as a problem hindering the ability of people with dementia to live at home. Loneliness may ensue from a loss of social contacts, the inability to build new social relationships or challenging behavior of the person with dementia.

\section{Behavioral problems}

The fourth problem domain put forward during five focus group interviews is related to the specific behaviors of people with dementia. First, a person with dementia may not be willing to accept care because the person does not see the necessity of help, which can lead to safety hazards. Second, the person with dementia can show certain behaviors, such as aggression, wandering, anxiety which are very burdensome for the person with dementia as well as the informal caregivers to deal with as the following quote indicates:

"I think that when a person with dementia exhibits certain behavior, especially when there is a partner, and the person with dementia is difficult to handle, difficult to manage, querulant, maybe aggressive, verbally or physically, that this can lead to a situation in which the partner is not able to deal with the situation any longer." (FG34)

These examples indicate that it is not the behavior itself that hinders the ability of people with dementia to live at home, but rather the consequences (e.g. safety hazard or increased burden of informal care) of these behaviors.

\section{Formal care-related problems}

In five of the six focus groups interviews, formal care-related problems were discussed. The problems regarding formal care can be summarized as a lack of availability of care services adapted to the needs of people with dementia/the informal caregivers and inappropriate coordination of care services With regard to the lack of suitable care services, one respondent mentioned: 
"What I (an informal caregiver) really miss are easily accessible places for people with dementia to stay overnight (...) to give me (the informal caregiver) the possibility to recover, to catch my breath, which would enable me to continue (the informal care) for a while." (FG44)

Besides a lack of respite care a lack of day-care facilities that meet the needs of the individual person with dementia who is not interested in mainstream activities (e.g. bingo or singing) was described. With regard to inappropriate coordination of care services, the respondents mentioned that, frequently, several formal care providers are involved in the care of community-dwelling people with dementia and that they are often unaware of each other's work. Moreover, it was described that sometimes too many caregivers are involved, which can have negative consequences on the behavior of people with dementia.

\section{Cognitive decline}

Cognitive decline was described less frequently during the focus group interviews (twice in one interview). The respondents described forgetfulness and a lack of ability to recognize things as hindering the ability to live at home.

\section{Discussion}

Important problem domains preventing people with dementia from living at home

In the present study, problems within three domains threatening the ability of people with dementia to live at home were described most frequently during all six focus group interviews and can therefore be regarded as the most important ones, namely problems involving decreased self-reliance, safety-related problems, and informal caregiver/social network-related problems. In addition, behavioral problems, formal care-related problems, anxiety, and decreased mobility and cognition were described, but less frequently. Our results of the identified problem domains are supported by the results of other studies describing problems regarding ADL activities and behavioral difficulties ${ }^{22}$ as well as decreased abilities to perform IADL activities. ${ }^{23}$ A recent study on causes of crisis situations, defined as situations in which immediate psychiatric interventions are needed by community-dwelling people with dementia, described problems relating to risks and hazards at home, family carer-related problems, problems involving memory and behavior, community services-related problems, physical health problems, and social and environmental changes. ${ }^{24}$ Social and environmental changes were not explicitly mentioned as problems that hinder the ability to live at home in the present study; possibly, these factors are more specifically related to a crisis, instead of the ability to live at home.

Our study adds knowledge by identifying that problems in the three domains, decreased self-reliance, safety-related problems, and informal caregiver/social network-related problems, seem to be the most important barriers for aging in place that nurses in communitybased dementia care should pay attention to. These problem domains are interrelated since the underlying problem of decreased selfreliance underscores the need for willing and able informal caregivers that can compensate for functional deficits and a lack of meaningful activities, provide structure and prevent risky behavior. Otherwise the person with dementia will experience decreased autonomy, quality of life, and dignity as well as increased risk of h hospitalization and institutionalization. ${ }^{25}$ The data might indicate that an optimal amount of support exists to enable persons with dementia to prolong living at home. It was described that too many professionals being involved in care can cause coordination prob- lems. While too few informal caregivers being available, may cause a lack of practical and emotional support. In both situations the ability of the person with dementia to live at home might be threatened. Moreover, it needs to be recognized that proving informal care can be very burdensome and can lead to a situation in which the burden exceeds the personal capabilities of the caregivers. Therefore, it is essential to tackle not only problems that people with dementia are experiencing directly but also those problems related to informal caregivers and their social network in order to delay or prevent nursing home admission.

\section{Implications for practice and research}

Knowledge of the most important problem domains facilitate nurses to target their efforts in early detection so that they can intervene as soon with (innovative) solutions to prevent transfer to nursing homes. To support self-reliance, technological solutions may be employed such as medication dispensers with a reminder function, tools to apply and remove compression stockings, ${ }^{26}$ audible or visual prompts for other ADL activities such as eating or drinking, or specific clocks or agendas for people with dementia to facilitate a daily structure. ${ }^{27}$ For safety-related problems, of the caregiver can consider GPS tracking devices for people who tend to wander, fall sensors, systems to shut of the gas or water to prevent injuries at home, ${ }^{27}$ or lifestyle monitoring to assess deviant behavioral patterns from a distance. ${ }^{26}$ Solutions to support informal caregivers are also currently available. Examples of solutions to reduce caregiver burden or to increase caregivers well-being are: adult day care, respite care, ${ }^{28}$ educational programs for informal caregivers $^{29}$ or internet-based support interventions for informal caregivers. ${ }^{30}$

People with dementia and their informal caregivers are often unaware of the available treatment options for their practical problems. ${ }^{14}$ Hence, professionals (e.g. district nurses and case managers) can play an important role in detecting those problems, introducing possible solutions and coordinating these solutions. As one person with dementia is not like the other, each individual might face different combinations of practical problems. Since they might have different resources to compensate for their deficiencies, an individualized approach would be advisable when it comes to assessment of problems and a search for possible solutions. What is considered an optimal solution for one person might not be suitable for another. Moreover, new (technological) solutions are constantly developed and become available for implementation in practice. Thus, it can be challenging for nurses to keep up to date on the available solutions and to choose the right solution for the individual person. In addition, it must be considered that a certain infrastructure is needed to implement more complex technological solutions, such as telecare systems. Therefore, to fulfill their advisory role, nurses need to have detailed information on the solutions and their requirements for implementation. To obtain this information is to access general databases for assistive technology such as EASTIN ${ }^{31}$ and AbleData. ${ }^{32}$ However, those general databases might not contain all dementia-specific solutions and solutions beyond the scope of assistive technology. An area for further research might be the development and evaluation of a (computerized) decision support tool specifically developed for nurses in community-based dementia care. This might be helpful to facilitate nurses in their advisory role. Such a tool could match possible solutions for specific identified problems.

The aim to detect problems early and to introduce solutions is in line with an international attempt to facilitate people to live well with dementia, which was one of the main themes of the first international WHO Ministerial Conference on Global Action against Dementia held in 2015. The conference stressed that it is essen- 
tial to empower people with dementia to participate in society as much as possible. ${ }^{33}$ Any effort to empower people with dementia assumes that people have abilities to cope with deficiencies caused by their disease. This is also one of the underlying assumptions of the new definition of health "as the ability to adapt and to self-manage." ${ }^{34(\mathrm{p} 2)}$ One dimension within this definition is social health, which is described as a "dynamic balance between opportunities and limitations, shifting through life and affected by external conditions such as social and environmental challenges." ${ }^{34(\mathrm{p} 2)}$ This underpins the importance of detecting practical problems that people with dementia and their informal caregivers experience, which threaten this balance in daily life, and finding suitable solutions to recover the balance between opportunities and limitations.

\section{Considerations and limitations}

First, we included mainly professionals, and we conducted the member check with a selective sample of professionals. However, this was a conscious choice, because professionals with a coordinating function (such as home care nurses and case managers) in community-based dementia care were expected to be a good and reliable source of information about frequently occurring practical problems in daily life. They have experienced many transitions of people with dementia from the home to a nursing home, whereas people with dementia and informal caregivers can only report about their own case. We deliberately included a small group of informal caregivers and patient representatives to validate whether the problems described by them differ considerably from those put forward by the professionals; as this was not the case, we decided to include only this limited number. People with dementia were not included in this study those who had experienced problems threatening their ability to live at home are expected to be in an advanced stage of the disease, in which they could not meaningfully participate in such an interview. Second, the focus of this study was to explore the most important practical problems in daily life by using sticky notes to gather information. This, on the one hand, ensured that every participant got an equal chance to share his/ her view during the interview. On the other hand, it might have limited the richness of descriptions of the practical problems because people were forced to write down their ideas in a few words. However, during the interviews, the moderators tried to stimulate the participants to express their opinions in more detail by providing examples where possible. Finally, the participants were asked to indicate what were, according to them, the most important problems preventing people with dementia from living at home. What is seen as important may be a rather subjective interpretation. However, since certain problems were described consistently throughout the focus groups, it seems that those problems occurred frequently and therefore were regarded as important barriers for living at home. Nevertheless, to validate whether those problems can be generalized to a larger population, a longitudinal cohort study is recommended.

\section{Conclusion}

To facilitate aging in place and/or delay institutionalization of people with dementia, nurses in community-based dementia care should focus on detecting problems in the domains of decreased self-reliance, safety-related problems, and informal care/social network-related problems. Moreover, they should be able to advise people with dementia and their informal caregivers on possible solutions to deal with the daily struggles they encounter within these three domains.

\section{Acknowledgments}

We would like to thank the participants of the focus groups for their valuable contribution to this study. In addition, we wish to thank Dr. Hilde Verbeek, who led two of the six focus group discussions and supported us with feedback on the manuscript. Moreover, we thank Nadine Spierts, who joined one focus group interview as a facilitator/observer and who supported us in the categorization and analysis of the data. Finally, we would like to thank Professor Dr. Liz Capezuti for her valuable comments on the manuscript.

\section{References}

1. World Health Organization, Alzheimer's Disease International. Dementia: A public health priority. http://apps.who.int/iris/bitstream/10665/75263/1/ 9789241564458_eng.pdf?ua=1; Published 2012. Accessed October 2014.

2. Prince M, Prina M, Guerchet M. World Alzheimer Report 2013. Journey of caring. An analysis of long-term care for dementia. https://www.alz.co.uk/research/ WorldAlzheimerReport2013.pdf; Published 2013. Accessed October 2014.

3. Alzheimer Nederland. Wat is dementie? http://www.alzheimer-nederland.nl/ informatie/wat-is-dementie.aspx. Accessed 7 July 2015.

4. Peeters J, De Lange J, Van Asch I, Spreeuwenberg P, Veerbeek M, Pot A, Francke A. Landelijke evaluatie van casemanagement dementie. http://www.nivel.nl/ sites/default/files/bestanden/rapport-casemanagement-dementie.pdf; Published 2012. Accessed October 2014.

5. Meijer S, van der Noordt M. Zorggebruik bij dementie. https://www. volksgezondheidenzorg.info/onderwerp/dementie/preventie-zorg/zorg\# methoden. Accessed 09 June 2017.

6. Eaker ED, Vierkant RA, Mickel SF. Predictors of nursing home admission and/or death in incident Alzheimer's disease and other dementia cases compared to controls: a population-based study. J Clin Epidemiol. 2002:55:462-468.

7. von Kutzleben M, Schmid W, Halek M, Holle B, Bartholomeyczik S. Communitydwelling persons with dementia: what do they need? What do they demand? What do they do? A systematic review on the subjective experiences of persons with dementia. Aging Ment Health. 2012;16:378-390.

8. Moïse P, Schwarzinger M, Um M. Dementia care in 9 OECD countries. http:// dx.doi.org/10.1787/485700737071; Published 2004. Accessed October 2014.

9. Maarse JAM, Jeurissen PP. The policy and politics of the 2015 long-term care reform in The Netherlands. Health Policy. 2016;120:241-245.

10. Janssen D, Jongen W, Schröder-Bäck P. Exploring the impact of austerity-driven policy reforms on the quality of the long-term care provision for older people in Belgium and The Netherlands. J Aging Stud. 2016;38:92-104.

11. Gaugler JE, Yu F, Krichbaum K, Wyman JF. Predictors of nursing home admission for persons with dementia. Med Care. 2009;47:191-198.

12. Luppa M, Luck T, Brahler E, Konig HH, Riedel-Heller SG. Prediction of institutionalisation in dementia. A systematic review. Dement Geriatr Cogn. 2008;26:65-78.

13. Verbeek H, Meyer G, Challis D, et al. Inter-country exploration of factors associated with admission to long-term institutional dementia care: evidence from the RightTimePlaceCare study. J Adv Nurs. 2015;71:1338-1350.

14. Wolfs CA, de Vugt ME, Verkaaik M, Verkade PJ, Verhey FR. Empowered or overpowered? Service use, needs, wants and demands in elderly patients with cognitive impairments. Int J Geriatr Psych. 2010;25:1006-1012.

15. van der Roest HG, Meiland FJ, Comijs HC, et al. What do community-dwelling people with dementia need? A survey of those who are known to care and welfare services. Int Psychogeriatr. 2009;21:949-965.

16. Polit DF, Beck C. Nursing Research: Appraising Evidence for Nursing Practice. 7th ed. Philadelphia: Wolters Kluwer Health | Lippincott Williams \& Wilkins; 2010.

17. Afram B, Verbeek $\mathrm{H}$, Bleijlevens $\mathrm{MH}$, et al. Predicting institutional long-term care admission in dementia: a mixed-methods study of informal caregivers' reports. J Adv Nurs. 2014;71:1351-1362.

18. METAPLAN-Gesellschaft für Planung und Organisation. Fibel zur Metaplantechnik: Wie man mit der Metaplantechnik Gruppengespräche moderiert. http://www.sswm.info/sites/default/files/reference_attachments/ METAPLAN\%20GMBH\%20a\%20ny\%20Fibel\%20zur\%20MetaplantechnikGERMAN.pdf; Published n.d. Accessed July 2014.

19. Graneheim UH, Lundman B. Qualitative content analysis in nursing research: concepts, procedures and measures to achieve trustworthiness. Nurs Educ Today. 2004;24:105-112.

20. Polit DF, Beck CT. Nursing Research: Generating and Assessing Evidence for Nursing Practice. Philadelphia: Wolters Kluwer/Lippincott Williams \& Wilkins; 2012.

21. Polit DF, Beck CT. Essentials of Nursing Research: Appraising Evidence for Nursing Practice. Philadelphia: Wolters Kluwer Health/Lippincott Williams \& Williams; 2013.

22. Risco E, Cabrera E, Jolley D, et al. The association between physical dependency and the presence of neuropsychiatric symptoms, with the admission of people with dementia to a long-term care institution: a prospective observational cohort study. Int J Nurs Stud. 2015;52:980-987. 
23. Giebel CM, Challis D, Montaldi D. Understanding the cognitive underpinnings of functional impairments in early dementia: a review. Aging Ment Health. 2015;19:859-875.

24. Toot S, Hoe J, Ledgerd R, Burnell K, Devine M, Orrell M. Causes of crises and appropriate interventions: the views of people with dementia, carers and healthcare professionals. Aging Ment Health. 2013;17:328-335

25. Soto ME, Vellas B. Competence Assessment in Dementia. Wien: Springer-Verlag; 2008.

26. Thoma-Lürken T, Bleijlevens MH, Lexis MA, Hamers JP, de Witte LP. An overview of potential labor-saving and quality-improving innovations in long-term care for older people. J Am Med Dir Assoc. 2015;16:482-489.

27. Gibson G, Newton L, Pritchard G, Finch T, Brittain K, Robinson L. The provision of assistive technology products and services for people with dementia in the United Kingdom. Dementia. 2014;5:681-701.

28. Vandepitte Sophie S. Effectiveness of respite care in supporting informal caregivers of persons with dementia: a systematic review. Int J Geriatr Psych. 2016;31:1277-1288
29. Jensen M, Agbata IN, Canavan M, McCarthy G. Effectiveness of educational interventions for informal caregivers of individuals with dementia residing in the community: systematic review and meta-analysis of randomised controlled trials. Int J Geriatr Psychiatry. 2015;30:130-143.

30. Boots LM, de Vugt ME, van Knippenberg RJ, Kempen GI, Verhey FR. A systematic review of Internet-based supportive interventions for caregivers of patients with dementia. Int J Geriatr Psychiatry. 2014;29:331-344.

31. EASTIN Association. European Assistive Technology Information Network. http://www.eastin.eu/nl-nl/searches/products/index. Accessed 3 March 2017.

32. AbleData. AbleData Tools en Technology to Enhance life. http://www. abledata.com/. Accessed 3 March 2017.

33. World Health Organization. Global action against dementia. http://apps.who.int/ iris/bitstream/10665/179537/1/9789241509114_eng.pdf; Published 2015. Accessed October 2016

34. Huber M, Knottnerus JA, Green L, et al. How should we define health? BMJ. 2011;343:d4163. 